\title{
Lithium Promotes Adult Neural Progenitor Differentiation Via GSK3ß- Dependent Signaling Pathways
}

\author{
Heinrich F. Bürgers ${ }^{1}$, Dominik W. Schelshorn ${ }^{1}$, Wolfgang Kuschinsky ${ }^{1}$ and Martin H. Maurer*,1,2 \\ ${ }^{I}$ Department of Physiology and Pathophysiology, Division of Systems Physiology, University of Heidelberg, Im Neuen- \\ heimer Feld 326, 69120 Heidelberg, Germany and ${ }^{2}$ Present address: SYGNIS Bioscience GmbH \& Co. KG, Im Neuen- \\ heimer Feld 515, 69120 Heidelberg, Germany
}

\begin{abstract}
Lithium is one of the standard drugs in the treatment of bipolar disorder, although its molecular modes of action are not well understood. It is a potent inhibitor of the multifunctional enzyme Glycogen Synthase Kinase $3 ß$ (GSK3ß), which also plays a central role in neurogenesis via the developmental Wnt signaling pathway. In the present study, we analyzed the influence of lithium on GSK3ß signaling in adult neural progenitor cells (NPCs) from the rat subventricular zone. Protein expression patterns of NPCs cultured in the presence of $20 \mathrm{mM}$ lithium chloride were compared to those of untreated cells. A proteomic approach based on two-dimensional gel electrophoresis and mass spectrometry showed changes in several GSK3ß-related proteins. We demonstrate the inhibition of GSK3ß by stabilization and nuclear transfer of its downstream target, $ß$-catenin. Moreover, the phosphorylated (=inhibited) GSK3ß protein was strongly enriched in the nuclear fraction of lithium-treated cells. The fraction of cells differentiated into astroglia increased moderately, and the fraction of cells differentiated into neurons increased strongly, as shown by immunostaining. In conclusion, lithium promotes NPC differentiation, mainly to neurons, via GSK3ß-related pathways.
\end{abstract}

Key Words: Adult neural progenitor cell, Lithium, Two-dimensional gel electrophoresis, Rat.

\section{INTRODUCTION}

Although lithium is one of the standard drugs used in the treatment of bipolar disorder [1,2], its molecular modes of action in these disorders are still unknown. Lithium is a potent inhibitor of Glycogen Synthase Kinase 3ß (GSK3ß), a multifunctional enzyme involved in glycogen metabolism, cell polarity, cytoskeleton formation, cell survival, and transcriptional control [3-5]. In this context, the molecular action of lithium in bipolar disorder is mainly based on GSK3ßdependent signaling [6-10]. Further effects of lithium on cellular signaling are mediated by the inositol phosphate pathway [11-13]. Other cellular signals influenced by mood stabilizers and antidepressants are mediated by the 5hydroxytryptamine (5HT, serotonin) receptor and BrainDerived Neurotrophic Factor (BDNF) receptor [14].

In recent years, abnormalities in neural progenitor cell (NPC) survival, migration, and differentiation have been discussed as causes of pathogenesis of bipolar disorder (reviewed in [15]), although no direct evidence for impaired neurogenesis in humans with bipolar disorder exist. In the event that neurogenesis is involved in the pathogenesis of bipolar disorder, new treatment options may arise. One of the central developmental pathways in neurogenesis is Wnt signaling, where GSK3ß coordinates cell growth and polarity $[16,17]$. Wnt signaling is also active in adult neural stem/progenitor cells of the rat brain [18]. Downstream signaling of GSK3ß involves the cytoplasmic stabilization of B-catenin, which is then translocated to the nucleus and

*Address correspondence to this author at the Dept. of Physiology and Pathophysiology, University of Heidelberg, Im Neuenheimer Feld 326, 69120 Heidelberg, Germany; Tel: +49-6221-544075; Fax: +49-6221544561; E-mail: maurer@physiologie.uni-heidelberg.de interacts with the transcription factor TCF/Lef-1 [3]. Of note, phosphorylation of GSK3B inactivates the enzyme.

In the present study, we analyzed the influence of lithium on GSK3ß signaling in NPCs from the adult rat subventricular zone. First, we identified GSK3ß-related proteins in a proteomic approach comparing NPCs in the presence of lithium to untreated cells. We then demonstrate lithiuminduced inhibition of GSK $3 \beta$ by stabilization and nuclear transfer of its downstream target, $B$-catenin, and its phosphorylation using phospho-specific antibody staining for the GSK3ß protein. Next, we addressed the question how lithium-induced GSK3ß inhibition changes differentiation in NPCs.

\section{MATERIAL AND METHODS}

\section{Neural Progenitor Cell Cultures}

NPCs were isolated from adult rat brains using standard procedures as described previously $[19,20]$. Protocols are concordant with the policy on the use of animals, as endorsed by the European Communities Council Directive of 24 November 1986 (86/609/EEC) and the National Institutes of Health, and fulfill the local legal requirements. Subventricular zones of 6 rat brains were dissected, washed in $10 \mathrm{~mL}$ ice-cold Dulbecco's Phosphate Buffered Saline (DPBS) supplemented with $4.5 \mathrm{~g} / \mathrm{L}$ glucose (DPBS/Glc) and centrifuged for $5 \mathrm{~min}$ at $1600 \mathrm{x} \mathrm{g}$ at $4{ }^{\circ} \mathrm{C}$. The pellet was mechanically homogenized, resuspended in $20 \mathrm{~mL}$ DPBS/Glc, and centrifuged for $5 \mathrm{~min}$ at $1600 \mathrm{x} \mathrm{g}$ at $4{ }^{\circ} \mathrm{C}$. The pellet was enzymatically digested in $10 \mathrm{~mL}$ of $0.01 \%(\mathrm{w} / \mathrm{v})$ papain, $0.1 \%$ $(\mathrm{w} / \mathrm{v})$ dispase II (neutral protease), $0.01 \%(\mathrm{w} / \mathrm{v})$ DNase I, $12.4 \mathrm{mM}$ MgSO 4 in Hank's Balanced Salt Solution (HBSS), triturated by a plastic pipette tip, and incubated at room temperature for $40 \mathrm{~min}$. In three washing steps, the homogenate was centrifuged for $5 \mathrm{~min}$ at $1600 \mathrm{x} \mathrm{g} \mathrm{a} 4{ }^{\circ} \mathrm{C}$ and the pellet 
was resuspended in $10 \mathrm{~mL}$ Dulbecco's Modified Eagle's Medium (DMEM)-Ham's F12 medium supplemented with 100 units/mL penicillin, 100 units $/ \mathrm{mL}$ streptomycin, and 2 $\mathrm{mM}$ L-glutamine. Cells were resuspended in $1 \mathrm{~mL}$ neurobasal-B27 medium and the cell number was counted. Cells were plated in $2 \mathrm{~mL}$ dishes at 200,000 cells in B27neurobasal medium supplemented with 100 units $/ \mathrm{mL}$ penicillin, 100 units $/ \mathrm{mL}$ streptomycin, $20 \mathrm{ng} / \mathrm{mL}$ EGF, $20 \mathrm{ng} / \mathrm{mL}$ FGF-2, and $2 \mu \mathrm{g} / \mathrm{mL}$ heparin. About $0.8 \mathrm{~mL}$ of the medium was replaced weekly, and cells were passaged every 10-14 days. The NPCs were cultured for 6-10 weeks in $5 \% \mathrm{CO} 2$ at $37{ }^{\circ} \mathrm{C}$ before use. For inhibition of GSK3ß, cell cultures were incubated for 3 days in the presence of $20 \mathrm{mM}$ lithium chloride (Sigma-Aldrich, St. Louis, MO, USA).

\section{Cell Viability Assay}

Cell viability was measured using a colorimetric assay based on the reduction of tetrazolium salts by cellular dehydrogenases [21, 22] (CellTiter 96 AQueous One Solution Cell Proliferation Assay, Promega, Madison, WI, U.S.A.) according to the manufacturer's protocols.

\section{Two-Dimensional Gel Electrophoresis (2DE)}

2DE was performed using standard protocols as previously described [19, 20]. Cells were harvested and protein extraction for 2-DE was performed for $60 \mathrm{~min}$ at room temperature in a lysis buffer containing $7 \mathrm{M}$ urea, $2 \mathrm{M}$ thiourea, 4 $\%$ (w/v) CHAPS, $0.5 \%$ (v/v) Triton X-100, 100 mM DTT, $0.05 \%$ IPG buffer $\mathrm{pH}$ 3-10 (Amersham Biosciences, Uppsala, Sweden), and $0.156 \%$ (w/v) Complete protease inhibitor tablets (Roche, Mannheim, Germany). Four cell culture extracts were prepared as biological replicates. Sample protein amounts were determined by the Bradford method. A total of $250 \mu \mathrm{g}(5-10 \mu \mathrm{L})$ of the protein solution were suspended in rehydration solution consisting of $6 \mathrm{M}$ urea, $2 \mathrm{M}$ thiourea, 2 $\%$ (w/v) CHAPS, $0.5 \%$ (v/v) IPG buffer $\mathrm{pH} 3-10$, and a few grains of bromophenol blue to give a final volume of 350 $\mu \mathrm{L}$. The samples were applied to $\mathrm{pH} 3-10$ nonlinear gradient IEF gel strips for isoelectric focussing using the IPGphor apparatus (Amersham Biosciences, Uppsala, Sweden). The IEF gel strips were rehydrated for 12 hours at $30 \mathrm{~V}$ to remove high salt concentrations and to improve protein entry into the gel. Then $200 \mathrm{~V}, 500 \mathrm{~V}$ and $1000 \mathrm{~V}$ were applied for 1 hour each. Voltage was increased to $8000 \mathrm{~V}$ within $30 \mathrm{~min}$ and kept constant at $8000 \mathrm{~V}$ for 12 hours, resulting in a total of $100,300 \mathrm{Vh}$. Gel strips were equilibrated for $20 \mathrm{~min}$ each in an SDS equilibration buffer consisting of $50 \mathrm{mM}$ Tris$\mathrm{HCl}, \mathrm{pH} 8.8,6 \mathrm{M}$ urea, $30 \%$ (v/v) glycerol, $2 \%$ (w/v) SDS, a few grains of bromophenol blue, and $1 \%(\mathrm{w} / \mathrm{v})$ dithiothreitol or $2.5 \%(\mathrm{w} / \mathrm{v})$ iodoacetamide, respectively. The second dimension separation was performed using $12.5 \%$ polyacrylamide gels in the presence of $0.1 \%(\mathrm{w} / \mathrm{v})$ sodium dodecylsulfate. The gels were run at $30 \mathrm{~mA}$ for $30 \mathrm{~min}$ and $100 \mathrm{~mA}$ for about $4 \mathrm{~h}$ in a $20 \mathrm{~cm}$ x $20 \mathrm{~cm}$ water-cooled vertical electrophoresis apparatus (OWL, Woburn, MA, USA). For image analysis, gels were stained with the "Blue silver" stain [23]. Briefly, gels were soaked overnight in $0.12 \%$ Coomassie Blue G-250, $10 \%$ phosphoric acid, $10 \%$ ammonium sulfate, $20 \%$ methanol and destained the next day for 5-6 hours.

\section{Gel Image Analysis and Mass Spectrometry}

Gels were scanned and images were analyzed using the Phoretix 2D Expression software (Nonlinear Dynamics, Newcastle-upon-Tyne, UK). Image analysis was performed as described [24]. Normalized spot volumes defined as integral of spot area multiplied by optical densities were compared to normalized means \pm standard deviations from 4 biological replicate gels of each group by Student's t-test for unpaired data [25]. Spots of interest were excised and digested by trypsin for mass spectrometry (Centre for Molecular Medicine, ZMMK, University of Cologne, Germany). Mass spectra were obtained by MALDI-TOF-MS peptide mass fingerprinting and analyzed by searching the NCBI nonredundant protein database with Mascot [26] (http://www. matrixscience.com).

\section{Preparation of Cytoplasmic and Nuclear Protein Fractions}

Cells were harvested and centrifuged at 1,000 x $\mathrm{g}$ for 5 min. Most of the supernatant was discarded and in the rest of the supernatant cells were resuspended and centrifuged again at $1000 \mathrm{x} \mathrm{g}$ for $5 \mathrm{~min}$. The supernatant was discarded and pellets weighed. Pellets were resuspended in lysis buffer consisting of $15 \%$ sucrose, $10 \mathrm{mM}$ Tris- $\mathrm{HCl}, \mathrm{pH} 8.0,0.2$ mM EDTA, and Complete protease inhibitor (Roche, Mannheim, Germany) in a ratio of 1:3, mixed well, and centrifuged at $600 \mathrm{x}$ g for $15 \mathrm{~min}$. The nuclear pellet and supernatant containing cytoplasmic fraction were frozen separately at -20 ${ }^{\circ} \mathrm{C}$. Nuclear pellets were washed twice with $\mathrm{dH} 2 \mathrm{O}$ in order to remove EDTA which inhibits DNase I. Pellets were incubated with $10 \mu$ l of DNase I $(0.1 \mathrm{mg} / \mathrm{ml}$ in $1 \times$ DNase I buffer (10 X buffer consisting of $1 \mathrm{M}$ Tris- $\mathrm{Cl}(\mathrm{pH} 7.5), 25 \mathrm{mM}$ $\mathrm{MgCl} 2,5 \mathrm{mM} \mathrm{CaCl} 2$ in DEPC-H2O) for $20 \mathrm{~min}$ at $37{ }^{\circ} \mathrm{C}$. The incubated pellets were triturated through $20 \mathrm{G}$ syringes for several times in $50 \mu \mathrm{l} \mathrm{d} 2 \mathrm{O}$. The protein concentration was determined [27] and the samples were frozen at $-20{ }^{\circ} \mathrm{C}$.

\section{Western Blotting}

Protein extracts of the cytoplasmic and nuclear fractions were suspended in Laemmli sample buffer containing $0.5 \mathrm{M}$ Tris, $10 \%$ SDS, $10 \%$ glycerol, $0.05 \%$ bromophenol blue, and $5 \%$ 2-mercaptoethanol as described earlier [28], and denatured at $65{ }^{\circ} \mathrm{C}$ for $15 \mathrm{~min}$. Proteins were separated in $12.5 \%$ polyacrylamide gels and transferred to $0.2 \mu \mathrm{m}$ nitrocellulose membranes by electroblotting (300 mA for $30 \mathrm{~min}$ ). Membranes were blocked with blocking buffer (1X TBS, $0.1 \%$ Tween-20, 5\% (w/v) nonfat dry milk) for 1 hour at room temperature and stained with the specific antibody for GSK3ß (1:1,000; Cell Signaling Technologies, Danvers, MA, USA) and phosphoGSK3ßSer9 (1:1,000; Cell Signaling Technologies, Danvers, MA, USA), or B-catenin $(1: 2,000$; Chemicon, Temecula, CA, USA), respectively, and the secondary antibody HRP-IgG goat-anti-rabbit (1:10,000; Pierce, Rockford, IL, USA). Chemiluminescence was visualized by mixing $0.45 \mathrm{mM}$ p-coumaric acid, $12.5 \mathrm{mM}$ luminol [5-amino-2,3-dihydro-1,4-phthalazinedione] in $100 \mathrm{mM}$ Tris, pH 8.5, with $0.018 \% \mathrm{H} 2 \mathrm{O} 2$ in $100 \mathrm{mM}$ Tris, $\mathrm{pH} 8.5$ and exposure on X-ray films (MRDM; Eastman Kodak, Rochester, NY, USA) for 30-60 s. The bands were quantified using the Phoretix 2D Expression software (Nonlinear Dynamics, Newcastle-upon-Tyne, UK). 


\section{Immunostaining}

NPCs were grown adhesively on poly-L-lysine-coated cover slips for 7 days in presence of $\mathrm{LiCl}$ or under control conditions. The cells were fixed for $20 \mathrm{~min}$ in $4 \%$ paraformaldehyde in PBS, pH 7.4, with $0.2 \%$ Tween-20 (PBST). Slides were blocked $1 \mathrm{~h}$ at room temperature in Seablock (Pierce, Rockford, IL, USA) and incubated with the respective primary antibody overnight at $4{ }^{\circ} \mathrm{C}$ in a humidified chamber using primary antibodies against GFAP $(1: 1,000$; BD Biosciences, Heidelberg, Germany), and Tubulin-ßIII (clone TuJ-1; 1:1,000; Abcam, Cambridge, UK). The next day, slides were washed 3 times for $5 \mathrm{~min}$ in PBST and incubated with an appropriate fluorescent secondary antibody for $1 \mathrm{~h}$ at room temperature. The secondary antibody was anti-ms Cy2- or Cy3-conjugated IgG (1:200, Jackson ImmunoResearch, West Grove, PA, USA). After washing 3 times for $5 \mathrm{~min}$ each in TBST, nuclei were stained with 4',6diamidino-2-phenylindole (DAPI, 1:5,000, Molecular Probes, Eugene, OR, USA) for 1 min. Slides mounted in Mowiol-containing fluoprotective media [29] and stored at $4{ }^{\circ} \mathrm{C}$ in the dark until fluorescence microscopy was performed.

\section{Image Analysis and Cytometry}

Images were recorded using a digital camera (DC500, Leica, Bensheim, Germany) on a fluorescent microscope (DM-R HC, Leica Microsystems, Bensheim, Germany; BX50, Olympus, Hamburg, Germany). For image cytometry, images were analyzed using the TissueQuest software (TissueGnostics, Vienna, Austria) as described in detail [30]. Briefly, in the DAPI channel, nuclei were detected by dissection algorithms. Then immunopositive cells were detected by a non-annular signal growth algorithm around the nuclei. The signals for nestin, GFAP, and TuJ-1 were plotted against the DAPI signals to create FACS-like scattergrams.

\section{RESULTS}

\section{Lithium Decreases Cell Viability}

Comparing viable cells under different doses of $\mathrm{LiCl}$ in the cell culture media to untreated control NPCs, we found decreased numbers of NPCs in high doses of LiCl (Fig. 1). The ED50 was about $20 \mathrm{mM}$, thus we chose this concentration for further experiments.

\section{Lithium Alters the Expression of GSK3ß-Related Proteins}

In the present study, we used a proteomic approach to search for changes in the NPC protein expression pattern induced by lithium. Two-dimensional gels of whole cell lysates of NPCs from the subventricular zone of adult rats incubated in the presence of $\mathrm{LiCl}$ were compared to those of untreated control NPCs. In the gels of the experimental group exposed to $\mathrm{LiCl}$, we found a total of $285 \pm 123(\mathrm{~N}=4$ biological replicates) protein spots (ranging from 170 to 435), compared to $546 \pm 167$ ( $N=4$ biological replicates) in the control group (ranging from 238 to 858). We found the highest differential expression values for protein pathways involved in cytoskeletal reorganization and cellular energy metabolism (data not shown). Moreover, we found changes in the expression of proteins related to GSK3B, either as direct interaction partners or protein targets modified by
GSK3ß, or as parts of the downstream signaling (Fig. 2, Table 1). Among the identified proteins, Ruvb-like protein-1 (Ruvbl1) is a DNA helicase which binds B-catenin, a downstream target of GSK3ß which regulates the transcriptional activity by binding of the transcription factor TCF/Lef-1 [31]. We identified two proteasome subunits, Psa1 and Psa6, which are involved in the degradation of cytoplasmic proteins, among them B-catenin. The Microtubule-associated protein RP/EB 1 (Mare1) binds the C-terminal domain of the Adenomatosis Polyposis Coli (APC) protein and forms a complex with axin and GSK3ß. This part of the Wnt signaling pathway is also involved in microtubule interaction, regulated by Rho GTPases. We identified the Rho GDPdissociation inhibitor protein 1 (Gdir), which is a negative regulator of Rho signaling and microtubule association.

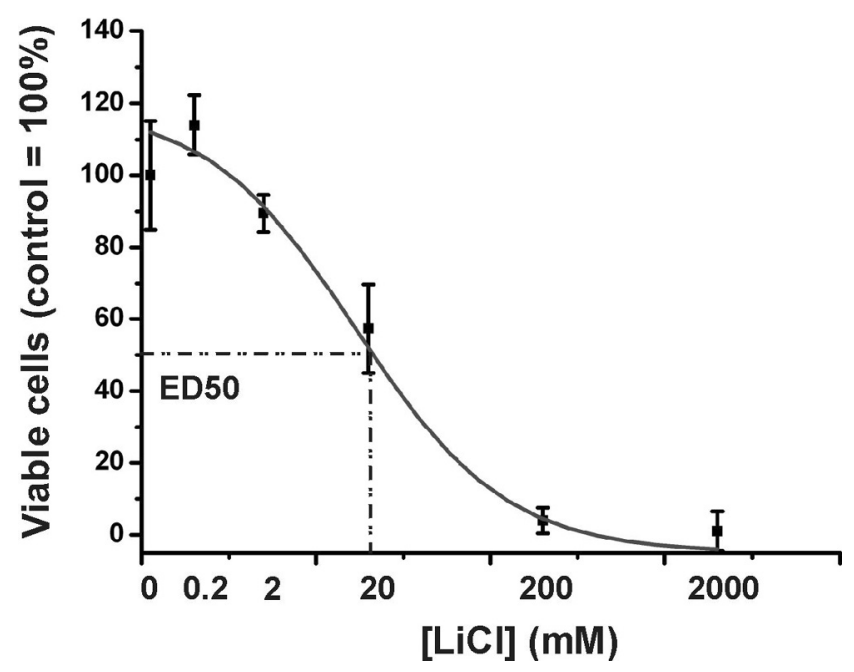

Fig. (1). Dose-response curve of lithium on cellular viability in the NPC cultures. The ED50 of about $20 \mathrm{mM}$ was used in the consecutive experiments.

\section{Inhibition of GSK3ß Activates Nuclear Transfer of B- catenin}

Downstream signaling of GSK3ß involves the cytoplasmic stabilization of $\beta$-catenin and its nuclear transfer, where B-catenin binds to the transcription factors TCF/Lef- 1 and $\mathrm{C} / \mathrm{EBP}$, resulting in the activation of gene transcription of a large number of target genes $[17,32]$ (http://www. stanford.edu/ rnusse/wntwindow.html). In the present study, we blotted cytoplasmic and nuclear extracts for localization of the B-catenin signal. Western blotting for B-catenin showed nearly no staining for control levels of $\beta$-catenin (Fig. 3), indicating its rapid degradation in the proteasome. In contrast, in the presence of $\mathrm{LiCl}, \beta$-catenin is stabilized in the cytoplasm (5-fold increase; $\mathrm{P}<0.0001 ; \mathrm{N}=3$ ). With regard to nuclear transfer, we found a baseline expression in the nuclear fraction of the control cells, which strongly increased in the presence of $\mathrm{LiCl}$ (2.5-fold increase, $\mathrm{P}<0.0001 ; \mathrm{N}=3$ ).

\section{Lithium Inhibits Nuclear GSK3ß Activity in NPCs}

GSK $3 ß$ is not only located in the cytoplasm, but also in the nucleus and in mitochondria [33], where it is closely related to the induction of apoptosis. In the present study, we compared cytoplasmic and nuclear protein extracts for 


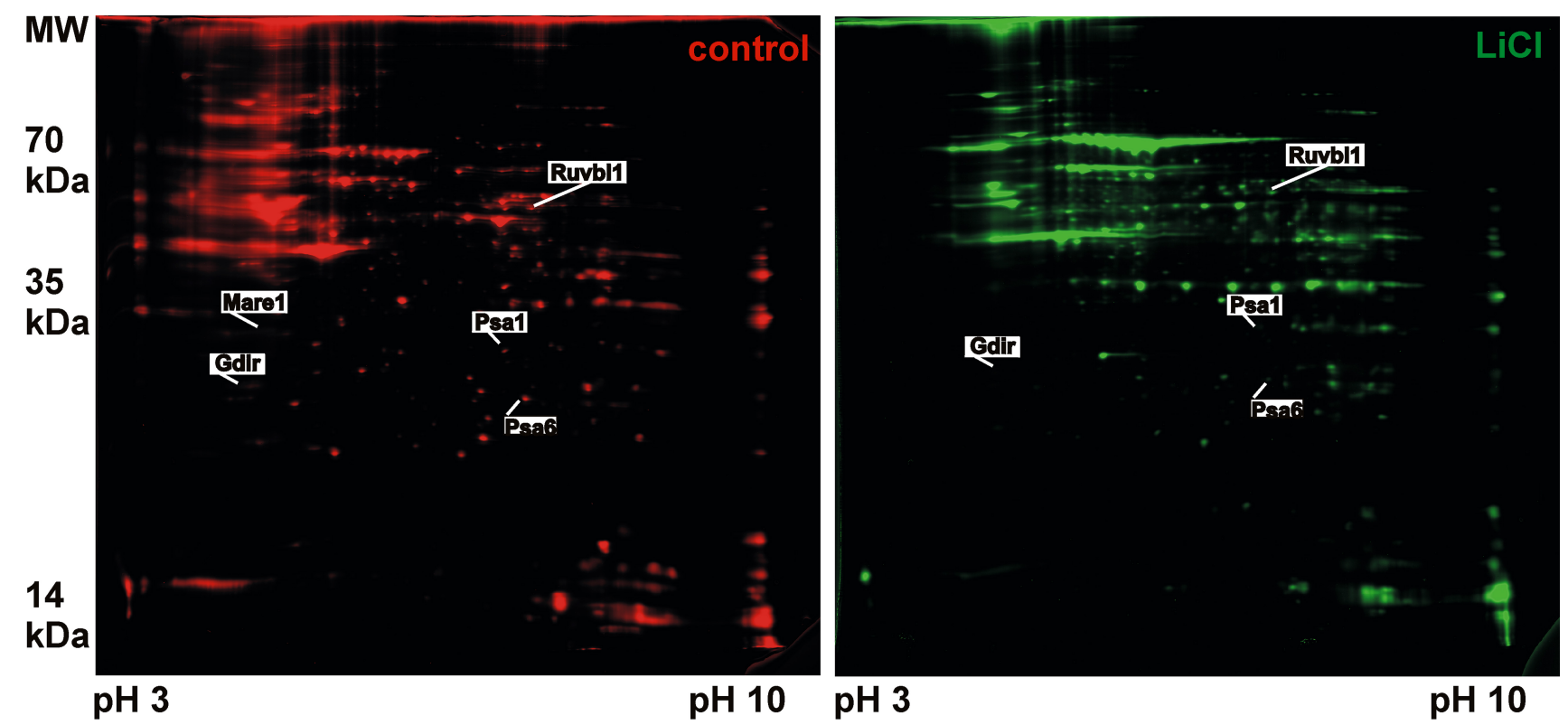

Fig. (2). Two-dimensional electropherograms of untreated subventricular zone (left, red) and LiCl-treated NPCs (right, green). Proteins of GSK3ß-related signaling are indicated by protein abbreviations (Table. 1).

Table 1. Differentially Expressed Proteins During Lithium Treatment of NPCs which are Related to GSK3ß in the Wnt Signaling Pathway. Proteins were Separated by Two-Dimensional Gel Electrophoresis and Identified by Mass Spectrometry (Fig. 2). Spot Volumes were Compared by Statistical Tests $(*, P<0.05, N=4)$

\begin{tabular}{|c|c|c|c|c|}
\hline Proteasome subunit, alpha type 1 & Psa1 & P18420 & degradates beta catenin and others & $-1.1(*)$ \\
\hline Rho GDP-dissociation inhibitor 1 & Gdir & Q99PT1 & binds rho & $+1.97(*)$ \\
\hline Microtubule associated protein RP/EB 1 & Mare1 & Q66HR2 & binds APC & only control $(*)$ \\
\hline
\end{tabular}

GSK3ß content by Western blot analysis. We compared cellular extracts from NPCs incubated in the presence of 20 $\mathrm{mM} \mathrm{LiCl}$ to untreated control cells. When probed with antiGSK3ß antibodies, the cytoplasmic fraction showed a 1.5fold increase in the LiCl-treated cultures $(\mathrm{P}<0.0003 ; \mathrm{N}=3$ ) (Fig. 4A). In contrast, the nuclear concentration of GSK3ß remained unchanged under exposure to $\mathrm{LiCl}$. Next, we used a phospho-GSK3ß-specific antibody to detect inactivated GSK3ß protein (pGSK3ß) (Fig. 4B). We did not find pGSK3B in the cytoplasm of control NPCs, but a pGSK3ß band occurred in the cytoplasm of LiCl-treated NPCs. In contrast, nuclear staining for pGSK3ß was detectable, and increased about 3-fold in the LiCl-treated cells $(\mathrm{P}<0.0238$; $\mathrm{N}=3$ ).

\section{Inhibition of GSK3ß Stimulates Neural Differentiation}

To evaluate the effects of lithium on cell differentiation, we compared the expression of cell differentiation markers after the application of $20 \mathrm{mM} \mathrm{LiCl}$ and compared the results to untreated NPCs ( $\mathrm{N}=5$ biological replicates). We used GFAP to detect astrocytes, and tubulin-BIII (TuJ1) to detect neurons. Whereas in the control NPCs only few GFAPpositive cells can be seen (Fig. 5A), Lithium increased the number of GFAP-positive cells. With regard to TuJ1 expression, no TuJ1-positive cells can bee seen in untreated controls (Fig. 5C), whereas lithium strongly induced TuJ1expression (Fig. 5D). Using the cytometry analysis software TissueQuest, we created FACS-like scattergrams of DAPI fluorescence intensity vs. GFAP or TuJ1 fluorescence intensities, respectively. We found an increased number of GFAP-positive cells in the presence of $\mathrm{LiCl}$ as compared to untreated controls (1.5-fold; Fig. 5E, F). With regard to TuJ1 staining, no positive cells are found in the untreated cells, whereas nearly all cells in the LiCl-treated cells became TuJ1-positive (Fig. 5G, H). These data indicate that lithium is a neural differentiation stimulus, increasing the number of neurons and astrocytes, with a stronger effect on neurogenesis. 


\section{control Cytopl. Nucl. Cytopl. Nucl.}

kDa

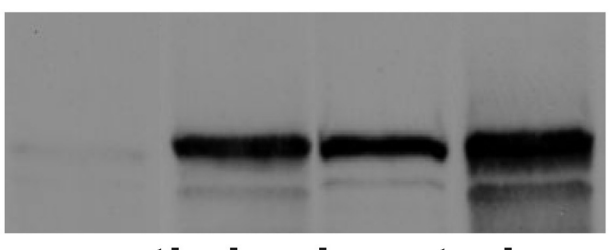

actin load control

45

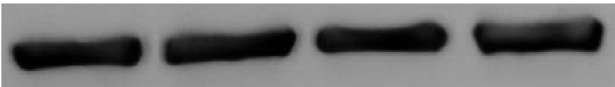

Fig. (3). Influence of lithium on nuclear translocation of $\beta$-catenin. Immunoblotting for B-catenin. Cytoplasmic and nuclear protein extracts of untreated NPCs and NPCs incubated in the presence of $\mathrm{LiCl}$. Two major bands can be seen at $80 \mathrm{kDa}$ and $96 \mathrm{kDa}$. Whereas only minimal staining for B-catenin can be seen in the cytoplasm of the controls, but to a higher content in the nucleus, lithium increases both the cytoplasmic and nuclear accumulation of ß-catenin.

\section{DISCUSSION}

\section{Lithium and GSK3ß-Related Signaling}

Lithium has long been used in clinical neurology and psychiatry as mood stabilizer in bipolar disorder, which affect up to $5 \%$ of the population at least once during life [1, 11]. The main advantage of lithium in comparison to other antipsychotic drugs used in the therapy of depression

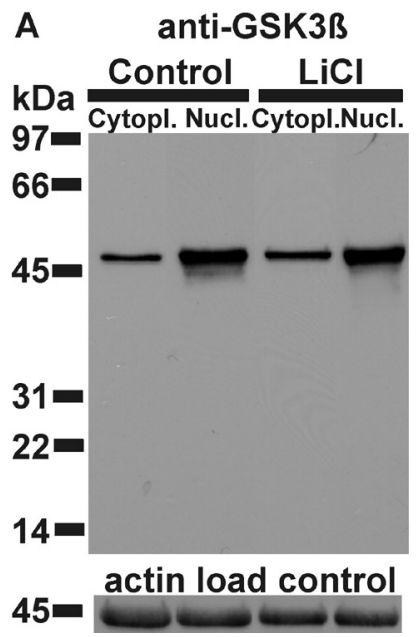

B anti-pGSK3ß

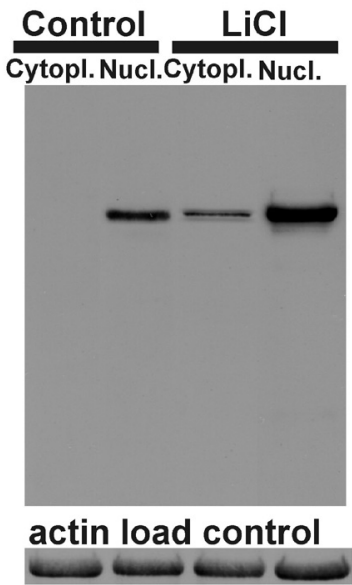

Fig. (4). Functional regulation of GSK3ß activity by LiCl. (A) Comparing cytoplasmic and nuclear protein extracts from NPCs in the presence of $\mathrm{LiCl}$ to untreated cells, we found 1.5-fold increased cytoplasmic levels of GSK3ß in the presence of $\mathrm{LiCl}$, but no changes in the nuclear concentrations. (B) Probing with a pGSK3ßspecific antibody, we found absent cytoplasmic pGSK3ß levels in the untreated NPCs, and pGSK3ß occurring in the cytoplasm of LiCl-treated NPCs. There was a 3-fold increase in nuclear levels of pGSK3ß under $\mathrm{LiCl}$ treatment.
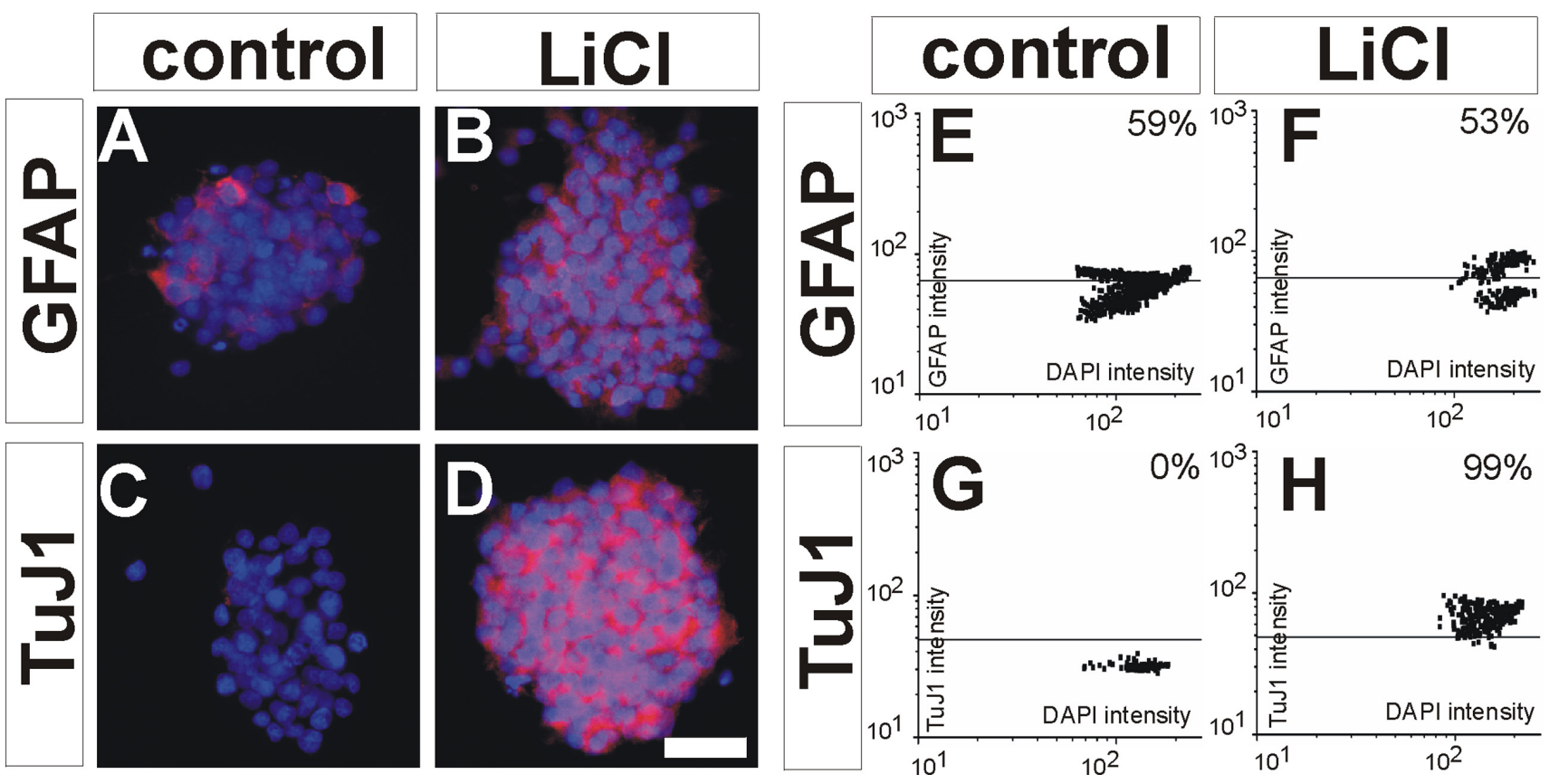

Fig. (5). Influence of lithium on neuronal and astrocytic marker expression in NPCs. (A) Control NPCs showed only few GFAP-positive cells. (B) Lithium increased the number of GFAP-positive cells about 1.5-fold. (C) No TuJ1-positive cells can be seen in untreated controls. (D) Lithium strongly induced TuJ1-expression in the NPCs (Scale bar, $10 \mu \mathrm{m})$. (E)-(H) Immunocytochemistry results using the TissueQuest analysis software. In the scattergrams, the DAPI fluorescence intensity is depicted on the x-axis, and the GFAP or TuJ1 fluorescence intensity on the y-axis. Detection thresholds are indicated by black lines. Single cell fluorescent signals results in single dots. (E, F) The FACS-like scattergram shows an increase in the cell number above the detection threshold in the presence of $\mathrm{LiCl}$ as compared to untreated controls. (G, H) With regard to TuJ1 staining, no positive cells are found in the untreated cells, whereas nearly all cells in the LiCl-treated cells became TuJ1-positive. These data show that the number of astrocytes and neurons increase under stimulation with lithium. 
seems to be its reduction in suicidality [1]. A major molecular mechanism of lithium action is the inhibition of GSK3ß, thus stabilizing B-catenin and mimicking Wnt signaling [34]. During development, Wnt signaling regulates neural precursor proliferation and apoptosis, stem cell self-renewal, lineage decision, as well as axon guidance and outgrowth [35, 36]. In the adult brain, Wnt signaling has been reported as an active signaling pathway in adult hippocampal neural stem/progenitor cells [18]. Moreover, lithium promotes adult hippocampal neural precursor proliferation [37]. In the present study, we found differentially expressed proteins related to GSK3ß signaling in NPCs cultures from the adult rat subventricular zone, when treated with lithium. This indicates that lithium is also an important inhibitor of GSK3ß in NPCs and activates its downstream signaling.

\section{Increase in Nuclear Transfer of B-Catenin by Inhibition of GSK3B}

The cellular target of GSK3ß conveying the transcriptional activation in the nucleus is $\beta$-catenin, a protein binding the transcription factors TCF/Lef- 1 and C/EBP [38]. In the present study, we found increased concentration of $ß$-catenin in the nuclear compartment during lithium treatment, thus confirming the inhibition of GSK3ß and activation of its downstream signaling via the $\beta$-catenin pathway in NPCs.

In B-catenin knock-out mice, the central nervous system is significantly smaller as well as the number of neuronal precursor cells, whereas in transgenic mice expressing constitutively activated $\beta$-catenin, the brain volume is enlarged $[39,40]$. Thus $\beta$-catenin seems to regulate the balance between neural precursor cell proliferation and differentiation. In the present study, we observed increased nuclear B-catenin levels associated with the activation of B-catenin/TCF/Lef-1specific gene transcription on the molecular level and increased neurogenesis on the morphological level.

\section{Lithium Treatment Promotes Neuronal Differentiation}

The effect of lithium on neural differentiation remains controversial, since increased neurogenesis has been found in P8 rat cerebellar granule cells and E17 rat cortical neurons [41], rat embryonic stem cells and striatal primordial stem cells [42], and the human teratocarcinoma cell line NTera2/D1 [43]. On the other hand, inhibition of neurogenesis by lithium has been found in mouse embryonic stem cells [44] and mouse teratocarcinoma cells [45].

In the present study, we tested the influence of lithium on differentiation of NPCs by immunostaining for marker proteins of the neuronal and glial lineages and subsequent cytometry. We found that lithium induced the appearance of significant numbers of both neurons and astrocytes, indicating that lithium promotes neurogenesis via transcriptional activation of $\beta$-catenin-dependent target genes. Other studies have also found increased numbers of neurons in adult rat neural stem cells in vitro [46] or in vivo [47]. In aged rats, this increase in differentiated neural cells seems to be lost [48].

The increased neurogenesis in the present study as well as in the literature has been attributed to decreased rates of apoptosis and neuroprotective effects of lithium [49]. Lithium strongly up-regulates the expression of anti-apoptotic proteins such as bcl-2 $[50,51]$ or by inhibition of proapoptotic proteins such as caspase-3 [52, 53].

\section{CONCLUSIONS}

The findings of the present study indicate that GSK3B signaling plays an essential role in regulating differentiation and proliferation of adult NPCs. Lithium treatment results in the inhibition of GSK3ß and transcriptional activation of distinct target genes of via $\beta$-catenin and TCF/Lef- 1 nuclear transfer. Lithium also produced larger numbers of neurons and astrocytes differentiated from NPCs.

\section{LIST OF ABBREVIATIONS}

$\begin{array}{lll}\text { GFAP } & = & \text { Glial Fibrillary Acidic Protein } \\ \text { GSK3ß } & = & \text { Glycogen Synthase Kinase 3ß } \\ \text { MALDI-TOF-MS } & = & \begin{array}{l}\text { Matrix Assisted Laser Desorption/ } \\ \text { Ionisation-Time of Flight mass } \\ \text { spectrometry }\end{array} \\ \text { NPC } & = & \text { Neural Progenitor Cell } \\ \text { pGSK3ß } & =\begin{array}{l}\text { phospho-Glycogen Synthase Kin- } \\ \text { ase 3ß }\end{array} \\ \text { TCF/Lef-1 } & =\begin{array}{l}\text { T Cell Factor/Lymphoid enhancer } \\ \text { factor(Lef) }\end{array}\end{array}$

\section{ACKNOWLEDGEMENTS}

We thank Mrs. Tilly Lorenz for technical assistance with two-dimensional gel electrophoresis, Mrs. Maria Harlacher for NPC cultures. This work was supported by the German Ministry of Education and Research (BMBF) within the National Genome Research Network NGFN-2 (01GS0496, to MHM and WK), the German Research Foundation (DFG, MA 2492/2-2, to MHM and WK) and the Estate of Friedrich Fischer (to MHM and HFB).

\section{REFERENCES}

[1] Freeman MP, Freeman SA. Lithium: clinical considerations in internal medicine. Am J Med 2006; 119: 478-81.

[2] Dubovsky SL. Treatment of bipolar depression. Psychiatr Clin North Am 2005; 28: 349-70.

[3] Woodgett JR. Judging a protein by more than its name: GSK-3. Sci STKE 2001; 2001: RE12.

[4] Frame S, Cohen P. GSK3 takes centre stage more than 20 years after its discovery. Biochem J 2001; 359: 1-16.

[5] Jope RS, Johnson GV. The glamour and gloom of glycogen synthase kinase-3. Trends Biochem Sci 2004; 29: 95-102.

[6] Gould TD, Chen G, Manji HK. In vivo evidence in the brain for lithium inhibition of glycogen synthase kinase-3. Neuropsychopharmacology 2004; 29: 32-8.

[7] Quiroz JA, Gould TD, Manji HK. Molecular effects of lithium. Mol Interven 2004; 4: 259-72.

[8] Woodgett JR. Physiological roles of glycogen synthase kinase-3: potential as a therapeutic target for diabetes and other disorders. Curr Drug Targets 2003; 3: 281-90.

[9] Gould TD, Manji HK. Glycogen synthase kinase-3: a putative molecular target for lithium mimetic drugs. Neuropsychopharmacology 2005; 30: 1223-37.

[10] Gomez-Ramos A, Dominguez J, Zafra D, et al. Inhibition of GSK3 dependent tau phosphorylation by metals. Curr Alzheimer Res 2006; 3: 123-7.

[11] Williams R, Ryves WJ, Dalton EC, et al. A molecular cell biology of lithium. Biochem Soc Trans 2004; 32: 799-802.

[12] Chen G, Manji HK. The extracellular signal-regulated kinase pathway: an emerging promising target for mood stabilizers. Curr Opin Psychiatry 2006; 19: 313-23. 
[13] Harwood AJ. Neurodevelopment and mood stabilizers. Curr Mol Med 2003; 3: 472-82.

[14] Coyle JT, Duman RS. Finding the intracellular signaling pathways affected by mood disorder treatments. Neuron 2003; 38: 157-60.

[15] Feldmann RE Jr, Sawa A, Seidler GH. Causality of stem cell based neurogenesis and depression - To be or not to be, is that the question? J Psychiatr Res 2007; 41: 713-23.

[16] Ciani L, Salinas PC. WNTs in the vertebrate nervous system: from patterning to neuronal connectivity. Nat Rev Neurosci 2005; 6: 351-62.

[17] Wodarz A, Nusse R. Mechanisms of Wnt signaling in development. Annu Rev Cell Dev Biol 1998; 14: 59-88.

[18] Lie DC, Colamarino SA, Song HJ, et al. Wnt signalling regulates adult hippocampal neurogenesis. Nature 2005; 437: 1370-5.

[19] Maurer MH, Feldmann RE, Fütterer CD, Butlin J, Kuschinsky W. Comprehensive proteome expression profiling of undifferentiated vs. differentiated neural stem cells from adult rat hippocampus. Neurochem Res 2004; 29: 1129-44.

[20] Maurer MH, Feldmann RE, Jr., Fütterer CD, Kuschinsky W. The proteome of neural stem cells from adult rat hippocampus. Proteome Sci 2003; 1: 4.

[21] Berridge MV, Tan AS. Characterization of the cellular reduction of 3-(4,5-dimethylthiazol-2-yl)-2,5-diphenyltetrazolium bromide (MTT): subcellular localization, substrate dependence, and involvement of mitochondrial electron transport in MTT reduction. Arch Biochem Biophys 1993; 303: 474-82.

[22] Cory AH, Owen TC, Barltrop JA, Cory JG. Use of an aqueous soluble tetrazolium/formazan assay for cell growth assays in culture. Cancer Commun 1991; 3: 207-12.

[23] Candiano G, Bruschi M, Musante L, et al. Blue silver: a very sensitive colloidal Coomassie G-250 staining for proteome analysis. Electrophoresis 2004; 25: 1327-33.

[24] Maurer MH. Software analysis of two-dimensional electrophoretic gels in proteomic experiments. Curr Bioinformatics 2006; 1: 25562.

[25] Maurer MH, Feldmann RE Jr, Brömme JO, Kalenka A. Comparison of statistical approaches for the analysis of proteome expression data of differentiating neural stem cells. J Proteome Res 2005; 4: $96-100$.

[26] Perkins DN, Pappin DJ, Creasy DM, Cottrell JS. Probability-based protein identification by searching sequence databases using mass spectrometry data. Electrophoresis 1999; 20: 3551-67.

[27] Bradford MM. A rapid and sensitive method for the quantitation of microgram quantities of protein utilizing the principle of proteindye binding. Anal Biochem 1976; 72: 248-54.

[28] Maurer MH, Geomor HK, Burgers HF, Schelshorn DW, Kuschinsky W. Adult neural stem cells express glucose transporters GLUT1 and GLUT3 and regulate GLUT3 expression. FEBS Lett 2006; 580: 4430-4.

[29] Osborn M, Weber K. Immunofluorescence and immunocytochemical procedures with affinity purified antibodies: tubulin containing structures. Methods Cell Biol 1982; 24: 97-132.

[30] Bürgers HF, Schelshorn DW, Wagner W, Kuschinsky W, Maurer MH. Acute anoxia stimulates proliferation in adult neural stem cells from the rat brain. Exp Brain Res 2008: 2008 Mar 11; [Epub ahead of print].

[31] Feng Y, Lee N, Fearon ER. TIP49 regulates beta-catenin-mediated neoplastic transformation and T-cell factor target gene induction via effects on chromatin remodeling. Cancer Res 2003; 63: 872634.

[32] Nusse R. WNT targets. Repression and activation. Trends Genet 1999; 15: 1-3.
[33] Bijur GN, Jope RS. Glycogen synthase kinase-3 beta is highly activated in nuclei and mitochondria. Neuroreport 2003; 14: 24159.

[34] Stambolic V, Ruel L, Woodgett JR. Lithium inhibits glycogen synthase kinase-3 activity and mimics wingless signalling in intact cells. Curr Biol 1996; 6: 1664-8.

[35] Ille F, Sommer L. Wnt signaling: multiple functions in neural development. Cell Mol Life Sci 2005; 62: 1100-8.

[36] Logan CY, Nusse R. The Wnt signaling pathway in development and disease. Annu Rev Cell Dev Biol 2004; 20: 781-810.

[37] Wexler EM, Geschwind DH, Palmer TD. Lithium regulates adult hippocampal progenitor development through canonical Wnt pathway activation. Mol Psychiatry 2008; 13: 285-92.

[38] Faisst S, Meyer S. Compilation of vertebrate-encoded transcription factors. Nucleic Acids Res 1992; 20: 3-26.

[39] Zechner D, Fujita Y, Hulsken J, et al. beta-Catenin signals regulate cell growth and the balance between progenitor cell expansion and differentiation in the nervous system. Dev Biol 2003; 258: 406-18.

[40] Chenn A. Eppendorf \& Science Prize. Essays on science and society. Making a bigger brain by regulating cell cycle exit. Science 2002; 298: 766-7.

[41] Hashimoto R, Senatorov V, Kanai H, Leeds P, Chuang DM. Lithium stimulates progenitor proliferation in cultured brain neurons. Neurosci 2003; 117: 55-61.

[42] Laeng P, Pitts RL, Lemire AL, et al. The mood stabilizer valproic acid stimulates GABA neurogenesis from rat forebrain stem cells. J Neurochem 2004; 91: 238-51.

[43] Misiuta IE, Saporta S, Sanberg PR, Zigova T, Willing AE. Influence of retinoic acid and lithium on proliferation and dopaminergic potential of human NT2 cells. J Neurosci Res 2006; 83: 66879.

[44] Aubert J, Dunstan H, Chambers I, Smith A. Functional gene screening in embryonic stem cells implicates Wnt antagonism in neural differentiation. Nat Biotechnol 2002; 20: 1240-5.

[45] Hasgekar NN, Gokhale PP, Amin MK, Seshadri R, Lalitha VS. Lithium inhibits growth in a murine neural precursor cell line. Cell Biol Int 1996; 20: 781-6.

[46] Kim JS, Chang MY, Yu IT, et al. Lithium selectively increases neuronal differentiation of hippocampal neural progenitor cells both in vitro and in vivo. J Neurochem 2004; 89: 324-36.

[47] Son H, Yu IT, Hwang SJ, et al. Lithium enhances long-term potentiation independently of hippocampal neurogenesis in the rat dentate gyrus. J Neurochem 2003; 85: 872-81.

[48] Yu IT, Kim JS, Lee SH, Lee YS, Son H. Chronic lithium enhances hippocampal long-term potentiation, but not neurogenesis, in the aged rat dentate gyrus. Biochem Biophys Res Commun 2003; 303: 1193-8.

[49] Manji HK, Moore GJ, Chen G. Clinical and preclinical evidence for the neurotrophic effects of mood stabilizers: implications for the pathophysiology and treatment of manic-depressive illness. Biol Psychiatry 2000; 48: 740-54.

[50] Chen G, Rajkowska G, Du F, Seraji-Bozorgzad N, Manji HK. Enhancement of hippocampal neurogenesis by lithium. J Neurochem 2000; 75: 1729-34.

[51] Wada A, Yokoo H, Yanagita T, Kobayashi H. Lithium: potential therapeutics against acute brain injuries and chronic neurodegenerative diseases. J Pharmacol Sci 2005; 99: 307-21.

[52] Shimomura A, Nomura R, Senda T. Lithium inhibits apoptosis of mouse neural progenitor cells. Neuroreport 2003; 14: 1779-82.

[53] Marks N, Saito M, Green M, et al. Opposite effects of lithium on proximal and distal caspases of immature and mature primary neurons correlate with earlier paradoxical actions on viability. Neurochem Res 2001; 26: 1311-20. 